\title{
Diversity of saproxylic beetle communities in chestnut agroforestry systems
}

\author{
Francesco Parisi ${ }^{(1-2)}$, \\ Fabio Lombardi ${ }^{(3)}$, \\ Pasquale Antonio Marziliano ${ }^{(3)}$, \\ Diego Russo ${ }^{(3)}$, \\ Antonio De Cristofaro ${ }^{(1)}$, \\ Marco Marchetti ${ }^{(4)}$, \\ Roberto Tognetti ${ }^{(1-5)}$
}

\begin{abstract}
Chestnut (Castanea sativa Mill.) has been exploited over the centuries for different uses. Nowadays, chestnut is mostly managed as coppice or orchard, creating a matrix of different forest structures. In particular, saproxylic species may provide information to correlate forest naturalness with stand structure. In this study, we evaluated how different management methods might influence the diversity of beetles hosted in chestnut agroforestry systems. Three management options were considered: young and mature coppice stands, and the traditional fruit orchard. Microhabitats occurring on veteran trees were also surveyed to investigate their effect on saproxylic communities, in the fruit orchard. The study area is located in Southern Italy, Aspromonte National Park, where Coleoptera were collected using window flight traps and the stand structural traits were also quantified. In the fruit orchard, a census of the occurring microhabitats was also realized. We used the following diversity indeces ( $\alpha$-diversity) to assess the state of conservation of the analysed forests: (i) Shannon Index; (ii) Margalef's Richness index; (iii) Equitability index; (iv) Dominance index. Results revealed that forest management have a fundamental role in influencing the diversity of Coleoptera communities and saproxylic beetles. A lower species richness was observed in the mature coppice in comparison with the young coppice and fruit orchard. Nevertheless, these agrofor estry systems, reflecting differentiated structural traits, allowed the development of highly specialized and threatened species $(34.3 \%$ included in IUCN risk categories), with important contribution to conservation of biodiversity in the rural landscape. Finally, the abundance and diversity of microhabitats in the traditional fruit orchard had positive effects on many saproxylic beetle families. These beetle communities, particularly saproxylic species, can be used as excellent bioindicators in actively managed agroforestry systems, suggesting sustainable forest management options for chestnut, while the conservation of veteran trees rich in microhabitats can be considered fundamental for preserving many endangered insects.
\end{abstract}

Keywords: Apennines, $\alpha$-diversity, Biodiversity Indicators, Chestnut Orchards, Coppice Stands, Forest Management, Threatened Species

al. 2012). Sustainable Development Goals (SDGs) encourage the protection of forest ecosystems and species diversity, which are fundamental to ensure the provision of

\section{Introduction}

Biodiversity conservation is a fundamental objective of sustainable forest manage ment (Lindenmayer et al. 2000, Lassauce et ecosystem services. In this sense, habitat diversity is especially relevant; for example, insects and other invertebrates have profound influences on the provision of ecosystems services (Dangles \& Jérôme 2019) and can be included among the indicator for Goal 15. Sustainable forest management considers the composition, structure and function of forest ecosystems as priority targets (Lassauce et al. 2012, Bouget et al. 2014), and highlights the role of biological diversity in supporting the provision of multiple forest ecosystem services (Manning et al. 2016). The relationships between species diversity and forest complexity have been investigated by estimating the species richness (Moning \& Müller 2009) Management types strongly influence the occurrence and abundance of microhabitats (MHs), in turn the diversity of coexisting species (Paillet et al. 2019, Parisi et al. 2020). Microhabitats occurring on living or standing dead trees constitute a particular and essential substrate or life site for species or communities to develop, feed, shel- 
ter or breed, during at least a part of their life cycle (Larrieu et al. 2018). In particular, the occurrence of saproxylics species is influenced by the occurrence and abundance of MHs, though these relationships are not always well understood across different geographical regions (Paillet et al. 2017), especially in Mediterranean environments.

Forest management influences the abundance and diversity of beetle (Coleoptera) communities, which have important ecological functions, being prey or predators themselves, but also pollinators, herbivores and decomposers (Redolfi De Zan et al. 2014). Beetle communities represent one of the most important and predominant components of forest ecosystems (Parisi et al. 2016). Coleoptera, particularly saproxylic beetles, i.e., organisms that depend upon wounded or decaying woody material during at least a stage of their life cycle (Stokland et al. 2012), are considered excellent bioindicators of health in forest ecosystems and, as such, useful to assess the sustainability of forest management (Lindenmayer et al. 2000). Traditional forest management approaches, applied to timber production, represent one of the main disturbances for rare or endangered saproxylic species (Stokland et al. 2012). However, studies on the effects of forest management on beetle communities has been mainly realized in boreal forests (Lassauce et al. 2011), while less studies linking structural attributes and saproxylic communities are available for Mediterranean mountain forests (Persiani et al. 2015, Sabatini et al. 2016, Bani et al. 2018, Parisi et al. 2019). Focusing on mountainous areas of Southern Europe, a gap of knowledge is particularly evident for chestnut (Castanea sativa Mill.) forests. Although several studies have shown the high ecological value and importance of these ecosystems to support a wide diversity of fauna and flora (Zlatanov et al. 2013), the relatioships between saproxylic beetle communities and the different management options of chestnut forests are almost unknown.

The EU Habitats Directive and Natura 2000 network recognize the importance of the chestnut stands (habitat 9260, Annex I), managed both as high forests and plantations, for biodiversity conservation (EC 2007). In particular, fruit orchards are in regression, having been converted into coppice stands, which has led to their abandonment. Currently, these systems are not threatened to completely disappear, though contraction phenomena are probable. For this reason, long-term monitoring protocols should be applied in permanent areas (Angelini et al. 2016). However, actions aimed at preserving the biodiversity of chestnut forests have been largely neglected, particularly in Mediterranean Europe, where harsh climatic conditions, long-lasting anthropic pressures, and fre-
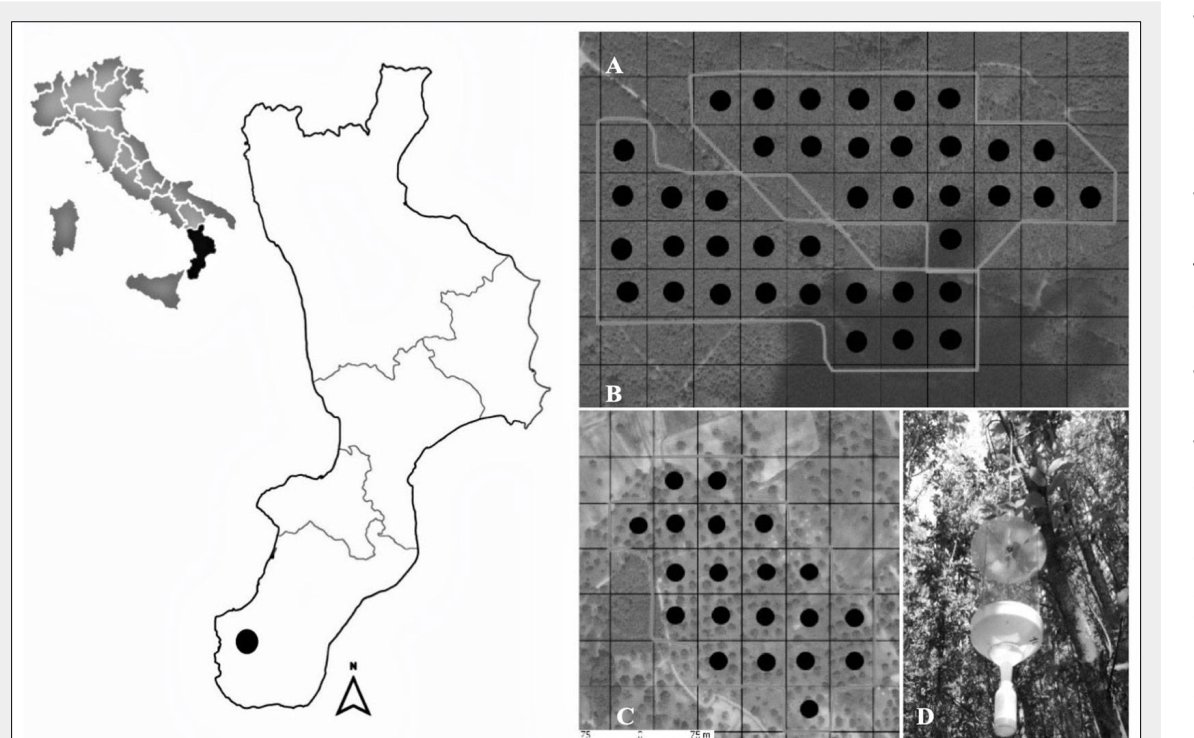

Fig. 1 - Location of the study area in Southern Apennines (Italy); black dots represent the location of the sampling plots, for each investigated area, where window flight traps were positioned. (A-A1): young coppice (YC); (B-B1): mature coppice (MC); (CC1): traditional fruit orchard (TO); (D): window flight trap positioned in each sampling plot.

quent forest fires have resulted in marked fragility of these ecosystems. In Italy, chestnut agroforestry systems cover an area of about 800,000 ha (Giannini et al. 2014); $70 \%$ of them are managed as coppices and the remaining 30\% as orchards for fruit production (Greco et al. 2018). They creates a landscape mosaic consisting of patches (habitats) in a matrix, in which different types of stand structures (young, mature and abandoned coppices, managed or abandoned fruit orchards) co-occur, influencing the composition of insect communities (Greco et al. 2018).

The prevalence of coppice stands over high stands is significant and related to the rapid growth rates and short rotation periods of chestnut, but also to the high vitality of stumps and resilience to stress factors, such as fires and diseases. Several authors have investigated the changes in biodiversity of different taxonomic groups in coppice stands (Joys et al. 2004, Lassauce et al. 2012), though only few of these in chestnut stands. Mattioli et al. (2016) has highlighted the relationships between silvicultural treatments and the floristic diversity of chestnut coppices, focusing on the rotation period. In particular, knowledge on the ecological inter-relationships between different types of management in chestnut stands is still very scarce for the Mediterranean area (Infusino et al. 2016).

Here we assess how different management types influence the a-diversity of beetles in chestnut forest stands in the Aspromonte National Park (Apennines, southern Italy). Specifically, we used the Coleoptera community and saproxylic beetles as ecological indicators. Three management options were considered: (i) young and (ii) mature coppice stands, and (iii) traditional fruit orchard. In addition, considering the ecological, environmental and cultural importance of the traditional fruit orchards in the Italian and European landscape (Conedera et al. 2004), the relationships between the MHs occurring on veteran trees and the saproxylic communities were also investigated. Veteran or monumental trees are habitats for many species, including several beetles listed in Annex II of the EU "Habitats" Directive 92/43/EEC, such as Osmoderma eremita (Coleoptera Scarabaeidae - Mosconi et al. 2017). Veteran trees, rich in $\mathrm{MHs}$, contribute to the conservation of saproxylic species (Siitonen \& Ranius 2015). In Italy, the Ministerial Decree 23/10/ 2014 identified seven criteria that should be met, jointly or alternatively, for the tree to be listed as monumental. These criteria are: 1 . significant age and size; 2 . peculiar shape; 3. ecological value; 4 . botanic rarity; 5. plant architecture; 6 . landscape value and 7 . historic-cultural-religious aspects. We hypothesized that: (i) the difference in complexity between coppice stands and the fruit orchard is reflected in the diversity and abundance of the beetle communities in; (ii) the frequency and typology of MHs in the traditional chestnut orchards influ- 
ence the diversity of saproxylic beetles (specifically in the fruit orchard); (iii) the focus on saproxylic beetles allows to obtain indications on species diversity of all beetle communities in these agroforestry systems.

\section{Materials and methods}

\section{Study area}

The study was carried out in three different agroforestry systems dominated by chestnut: (i) young (YC, 2 years old) and (ii) mature (MC, 11 years old) coppice stands located in Santo Stefano in Aspromonte ( $38^{\circ} 10^{\prime} 48.798^{\prime \prime}$ N. $\left.15^{\circ} 47^{\prime} 03.51^{\prime \prime} \mathrm{E}\right)$; and (iii) traditional fruit orchard (TO, older than 80 years) located in Cardeto d'Aspromonte ( $38^{\circ} 03^{\prime} 36.66^{\prime \prime}$ N. $\left.15^{\circ} 46^{\prime} 53.82^{\prime \prime} \mathrm{E}\right)$.

The stands occur on similar ecological and environmental conditions, on the borders of the Aspromonte National Park (Calabrian Apennines - Fig. 1), along an altitudinal gradient ranging from 907 to $1059 \mathrm{~m}$ a.s.l. In the study area, chestnut fruit orchards, generally of limited extension, are mainly located near small urban areas, in a mosaic of agroforestry systems, which includes chestnut coppice stands and other sparse woodlands, as well as agricultural field crops.

The climate is temperate, typical of Mediterranean mountainous environments. Mean annual temperature is about $8{ }^{\circ} \mathrm{C}$, while average minimum and maximum monthly temperatures are $0.5^{\circ} \mathrm{C}$ (the coldest month) and $16{ }^{\circ} \mathrm{C}$ (the warmest month), respectively. Average total annual precipitation is $1200 \mathrm{~mm}$, mainly occurring over the winter season (Meteorological station of Gambarie d'Aspromonte, $1187 \mathrm{~m}$ a.s.l.). Summer aridity is almost absent as frequent orographic precipitation occurs, due to the exposure to the moist air deriving from the Tyrrhenian sea.

\section{Sampling scheme and dendrometric measurements}

Each analyzed management type extends on about 12 ha. A total of 60 sampling plots (20 per each management type) were established and located at a regular distance of $50 \mathrm{~m}$ to each other, following a systematic aligned grid (Fig. $1-$ A, B and C). For each sampling plot, UTM datum WGS84 COordinates (Zone $32 \mathrm{~T}$ ) and altitude ( $\mathrm{m}$ a.s.I.) were recorded using the Juno $\mathrm{SB}^{\circledast}$ Global Positioning System (Trimble, Sunnyvale, California). In YC and MC, each plot extended over $530 \mathrm{~m}^{2}$, while in TO each plot covered an area of $1963 \mathrm{~m}^{2}$.

Within each management type (YC, MC and TO), three randomly selected circular plots were established for dendrometric measurements. The following parameters were recorded: diameter at breast height $(\mathrm{DBH})$, canopy cover (through visual estimation), and total tree height. Veteran trees (orchard) have been identified by applying the criteria of the above-mentioned Ministerial Decree 23/10/2014. Tree volumes were calculated via double-entry volume equations reported for chestnut in Tabacchi et al. (2011).

\section{Sampling of beetle fauna}

The collection of Coleoptera was carried out using window flight traps (WFTs). At the center of each sampling plot, one WFT was positioned at a height of $2 \mathrm{~m}$ above the ground (Bouget et al. 2008). A total of 60 WFTs were placed, 20 for each of the three management types. Traps were checked approximately every 20 days, for a total of four surveys in 2017 (from June to October).

Systematics and nomenclature followed Bouchard et al. (2011) and Audisio et al. (2015). All the taxa collected during the field activities are alphabetically listed in Tab. S1 (Supplementary material). Species strictly considered as saproxylic (sensu Carpaneto et al. 2015) are also reported in Tab. S1, together with their risk category at the Italian level (Audisio et al. 2015, Carpaneto et al. 2015).

Collected saproxylic and non saproxylic species were grouped according to the prevalent trophic categories, defined as follows: (i) xylophagus (organisms feeding exclusively or largely from wood); (ii) saproxylophagus (organisms feeding exclusively or largely from fungus-infected wood); (iii) mycophagous (organisms feeding exclusively or largely on fungi); (iv) mycetobiontic (organisms feeding on carpophores of large Polyporales and other fungi living on old trees and stumps); (v) commensal (commensals of saproxylophagus/xylophagus or of other saproxylic insects); (vi) Sap-feeder (sap-feeders on trees attacked by xylophagus); (vii) predator (organisms that primarily obtain food killing and consuming other organisms); (viii) unknown (unknown or uncertain trophic category).

Regarding the IUCN risk categories, the sampled saproxylic beetles follows the Italian Red List (Audisio et al. 2015): Endangered (EN, 1 species); Vulnerable (VU, 4 species); Near Threatened (NT, 15 species); Data Deficient (DD, 2 species); and Least Concern (LC, 67 species). All the collected taxa are alphabetically listed in Tab. S1 (Supplementary material).

At a plot level, we quantified the abundance (i.e., number of trapped individuals) of each sampled species, which was used as a response variable in the following analyses.

\section{Diversity indices}

In this study, univariate indices were calculated combining the number of species and their abundance. Particularly, we calculated the following four diversity indices: (i) the Shannon Index, taking into account the number of individuals, as well as the number of taxa (eqn. 1):

$$
H_{i}=-\sum_{i} p_{i} \cdot \ln \left(p_{i}\right)
$$

with $p_{i}$ representing the share of one individual within all species that were collected; (ii) the Margalef's richness index (d), based on the relationship between the number of species (S) and the total number of individuals ( $n-$ eqn. 2 ):

$$
d=\frac{(S-1)}{\ln (n)}
$$

(iii) the Equitability index (also known as Pielou's evenness), which measures the evenness of individual distribution among taxa and is calculated as the ratio between the Shannon diversity index and the logarithm of the number of taxa; (iv) the Dominance index (= 1-Simpson index), that ranges from o (all taxa are equally present) to 1 (one taxon completely dominates the community - eqn. 3 ):

$$
D=\sum_{i}\left(\frac{n_{i}}{n}\right)^{2}
$$

with $n_{i}$ representing the number of individuals of the $i$-th taxon.

\section{Microhabitat survey}

The MHs were surveyed only in the traditional fruit orchard, and not considered for the two coppice stands, since they were characterized by high tree density with small stem diameters. These young structural features and the associated development stage do not allow the formation of MHs, which are usually linked to the presence of mature and veteran trees (Larrieu et al. 2018).

A set of $47 \mathrm{MHs}$, according to Larrieu et al. (2018) was recorded (Tab. 1). We surveyed the whole trees and deadwood components, carefully examining the trunk from the ground to the crown or the whole length of horizontal deadwood elements. Dead branches, stem cavities, substitute or secondary crown, mold pockets, occurring on old living trees and deadwood, were recorded. All the sampled MHs were related to the orchard components (e.g., living trees, crown deadwood, dead trees) and then related to the sampled insects occurring in these components.

\section{Statistical analysis}

For each univariate index, the confidence intervals were calculated through a bootstrap procedure (Dixon 1993). This allowed to evaluate for each diversity index significant differences between the agroforestry systems, both for all beetle communities and for the saproxylics only.

In order to assess the significance, the PERMANOVA statistical test (Permutational Analysis of Variance) was applied, which considers the values of similarities without any assumption about the data distribution (McArdle \& Anderson 2001). PERMANOVA test verifies the simultaneous responses of one or more variables for one or more factors in an ANOVA experimental model, calculating the $\mathrm{p}$-values through permutations (Marti 2001). Finally, the bootstrapped comparison of diversity indices was consid- 
Tab. 1 - Type, definition and description of the MHs recorded in TO (from Larrieu et al. 2018).

\begin{tabular}{|c|c|c|}
\hline Form & Group & MH form \\
\hline \multirow[t]{3}{*}{ Cavities l.s. } & $\begin{array}{l}\text { Woodpecker breeding } \\
\text { cavities }\end{array}$ & $\begin{array}{l}\text { Small woodpecker breeding cavity; } \\
\text { Medium-sized woodpecker breeding } \\
\text { cavity; Large woodpecker breeding } \\
\text { cavity; Woodpecker “flute” (breeding } \\
\text { cavity string) }\end{array}$ \\
\hline & Rot holes & $\begin{array}{l}\text { Trunk base rot hole; Trunk rot hole; Semi- } \\
\text { open trunk rot hole; Chimney trunk base } \\
\text { rot hole; Chimney trunk rot hole; Hollow } \\
\text { branch }\end{array}$ \\
\hline & $\begin{array}{l}\text { Insect galleries and bore } \\
\text { holes } \\
\text { Concavities }\end{array}$ & $\begin{array}{l}\text { Insect galleries and bore holes; Dendro- } \\
\text { telm (phytotelmata, water-filled hole); } \\
\text { Woodpecker foraging excavation; Trunk } \\
\text { bark-lined concavity }\end{array}$ \\
\hline \multirow[t]{2}{*}{$\begin{array}{l}\text { Tree injuries and } \\
\text { exposed wood }\end{array}$} & Exposed sapwood only & $\begin{array}{l}\text { Bark loss; Fire scar; Bark shelter; Bark } \\
\text { pocket }\end{array}$ \\
\hline & $\begin{array}{l}\text { Exposed sapwood and } \\
\text { heartwood }\end{array}$ & $\begin{array}{l}\text { Stem breakage; Limb breakage } \\
\text { (heartwood exposed); Crack; Lightning } \\
\text { scar; Fork split at the intersection }\end{array}$ \\
\hline Crown deadwood & Crown deadwood & $\begin{array}{l}\text { Dead branches; Dead top; Remaining } \\
\text { broken limb }\end{array}$ \\
\hline \multirow[t]{2}{*}{ Excrescences } & Twig tangles & Epicormic shoots \\
\hline & Burrs and cankers & Burr; Canker \\
\hline $\begin{array}{l}\text { Fruiting bodies of } \\
\text { saproxylic fungi } \\
\text { and slime moulds }\end{array}$ & $\begin{array}{l}\text { Perennial fungal fruiting } \\
\text { bodies (life span }>1 \mathrm{y} \text { ) } \\
\text { Ephemeral fungal fruiting } \\
\text { bodies and slime moulds }\end{array}$ & $\begin{array}{l}\text { Perennial polypore; Annual polypore, } \\
\text { Pulpy agaric, Pyrenomycete, Myxomycete }\end{array}$ \\
\hline \multirow{3}{*}{$\begin{array}{l}\text { Epiphytic, epixylic } \\
\text { and parasitic } \\
\text { structures }\end{array}$} & $\begin{array}{l}\text { Epiphytic or parasitic } \\
\text { crypto- and phanerogams }\end{array}$ & $\begin{array}{l}\text { Bryophytes; Foliose and fruticose lichens; } \\
\text { Ivy and lianas; Ferns; Mistletoe }\end{array}$ \\
\hline & Nests & Vertebrate nest; Invertebrate nest \\
\hline & Microsoils & Bark microsoil; Crown microsoil \\
\hline Fresh exudates & Fresh exudates & Sap run; Heavy resinosis \\
\hline
\end{tabular}

Tab. 2 - Mean values ( \pm standard deviation) of the main dendrometric parameters for the three management types. (Trees): number of trees; (DBH): diameter at breast height; $(\mathrm{Ht})$ : tree height; $(\mathrm{G})$ : basal area; $(\mathrm{V})$ : volume.

\begin{tabular}{lccccc}
\hline $\begin{array}{l}\text { Silvicultural } \\
\text { system }\end{array}$ & $\begin{array}{c}\text { Trees } \\
\left(\mathbf{N ~ h a}^{-1}\right)\end{array}$ & $\begin{array}{c}\text { DBH } \\
(\mathbf{c m})\end{array}$ & $\begin{array}{c}\mathrm{Ht} \\
(\mathbf{m})\end{array}$ & $\begin{array}{c}\mathrm{G} \\
\left(\mathbf{m}^{2} \mathbf{h a}^{-1}\right)\end{array}$ & $\begin{array}{c}\mathbf{V} \\
\left(\mathbf{m}^{3} \mathbf{h a}^{-1}\right)\end{array}$ \\
\hline YC & $23360 \pm 2700$ & $3.36 \pm 0.95$ & $2.2 \pm 0.75$ & $20.7 \pm 3.2$ & $28.8 \pm 3.4$ \\
\hline MC & $5814 \pm 904$ & $9.0 \pm 2.3$ & $7.7 \pm 1.3$ & $36.6 \pm 4.1$ & $168.31 \pm 21.5$ \\
\hline TO & $125 \pm 15$ & $74.7 \pm 10.1$ & $15.8 \pm 1.9$ & $54.81 \pm 3.9$ & $409.22 \pm 30.7$ \\
\hline
\end{tabular}

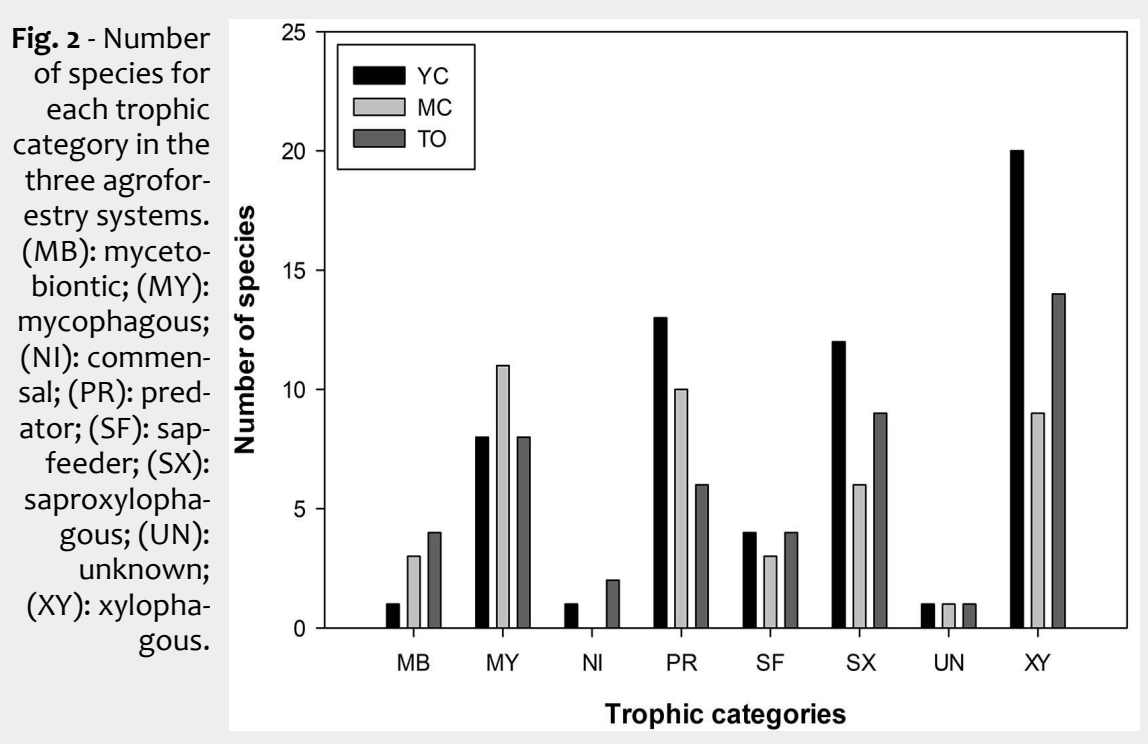

ered significant when the associated critical value (p) was lower than 0.05 . Surveyed $\mathrm{MHs}$ were firstly grouped according to the seven forms described in Larrieu et al. (2018): cavities, tree injuries and exposed wood, crown deadwood, excrescences, fruiting bodies of saproxylic fungi and slime molds, epixylic and parasitic structures and fresh exudates (first column in Tab. 1). Then, for each tree (living or dead) occurring in TO, we verified the relationships between the MHs and the saproxylic insects at a family level, using the Spearman's correlation coefficient.

\section{Results}

\section{Stand structural features}

The number of trees per hectare was 23,360 for YC and 5814 for MC. In TO, 125 trees per hectare were recorded (Tab. 2). In TO, we also observed the occurrence of trees having $\mathrm{DBH}>100 \mathrm{~cm}$ with a density of 37 trees ha-1; no veteran trees occurred in YC and in MC. The small standard deviation for the analyzed dendrometric parameters (Tab. 2) was related to the homogeneity of these stands. For the investigated parameters, the univariate analysis of variance revealed no significant differences between replications. The total canopy cover was $21 \%$ in $\mathrm{TO}, 86 \%$ in $\mathrm{MC}$ and $10 \%$ in $\mathrm{YC}$.

\section{Coleoptera analysis}

We collected 6282 specimens, belonging to 259 species. A total of 53 beetle families were detected. Among the sampled beetles, $34.3 \%$ were saproxylics, namely 3783 specimens belonging to 89 species and 53 families of Coleoptera (Tab. S1 in Supplementary material).

In TO 2986 individuals were collected, whereas 2255 in YC and 1041 in MC. Considering the number of sampled species, 164 different species were found in YC, 111 in $M C$ and 145 in TO. Furthermore, 43 of these species occurred in all the three agroforestry systems.

The most abundant species were Epuraea fuscicollis, Soronia oblonga and Acanthogethes fuscus (Nitidulidae family), with 1885, 1038 and 502 specimens, respectively. These species were $54.5 \%$ of the total sampled beetles. Moreover, Nitidulidae family represented $53.3 \%$ of the whole beetles captured, followed by Elateridae (5.74\%), Staphylinidae (3.51\%) and Curculionidae $(5.36 \%)$. Silphidae family (necrophagous beetles) were probably accidentally caught in the traps, due to attraction by moth and butterflies, and we decided to exclude them from further analysis.

In Fig. 2 the proportion of the collected species, grouped according to the prevalent trophic categories, is reported. Xylophagous represented $31 \%$ of the total sampled families, followed by predators (19\%), saproxylophagous (18\%), mycophagous $(16 \%)$, mycetobiontic $(8 \%)$, sap-feeder $(5 \%)$ and unknown (1\%). In YC, the categories xylophagous, saproxylophagous and preda- 
Fig. 3 - Median values and related variability of the diversity indices for young coppice (YC), mature coppice (MC) and traditional orchard (TO), both for all beetle communities and for the saproxylics only.
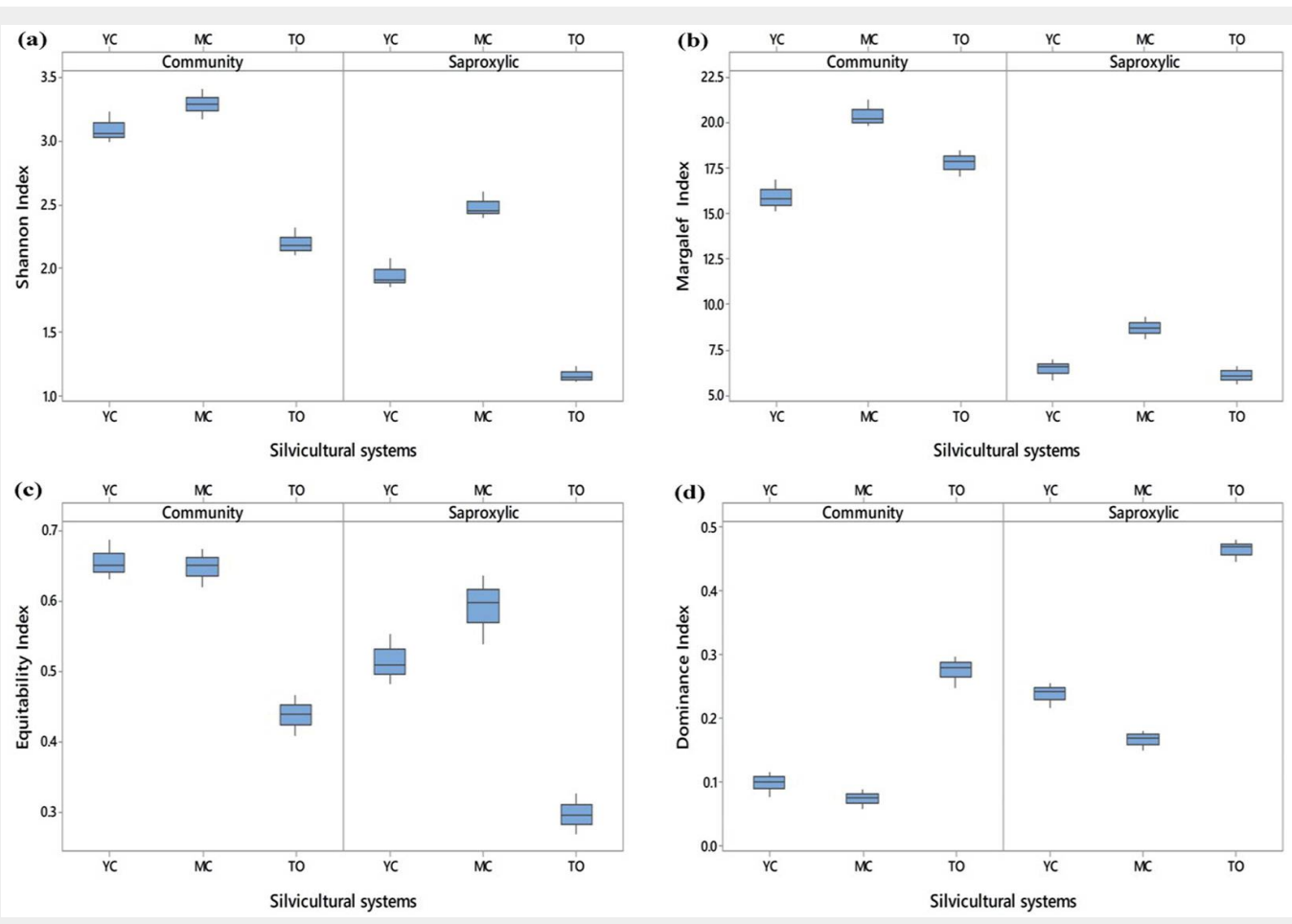



tor were predominant. Whereas, mycetophagous prevailed in MC, and predator and xylophagous were relatively important. The most represented categories in TO were xylophagous, saproxylophagous and mycetophagous. Predator decreased from YC to TO, while mycetobiontic increased from YC to TO. Sap-feeder were constant across the three agroforestry systems.

Beetle diversity in agroforestry systems Fig. 3 shows the values of diversity indices in the three stand types investigated, both for all beetle communities and for the saproxylics only.

In general, the diversity indices analyzed were always higher for all beetle communities than for the saproxylic community only, with the exception of the dominance index. This difference was strongly evident for the Margalef and Shannon index, since the number of individuals characterizing all beetle communities was higher than for the saproxylics (34.3\%). This difference was less evident in the equitability index, for which an evenness distribution of individuals was observed, both considering saproxylic and non-saproxylic species in three agroforestry systems. Finally, the dominance index had higher values in saproxylics than in all beetle communities, as in this component the Nitidulidae completely dominated the community.

Both for all beetle communities and for the saproxylics only, the diversity indices were always significantly lower in TO than in $Y C$ and $M C$, with the exception of the dominance index, which was significantly higher in TO than in YC and MC (Tab. 3). However, with reference to all beetle communities, no significant differences were observed between $Y C$ and $M C$, both for the Shannon index and for the dominance and equitability index. By contrast, the two coppice stands differed significantly between each other, when only the saproxylic community was considered, except for the equitability index (Tab. 3). Considering the saproxylic community, all the indices were significantly higher in $M C$ than in $Y C$ and TO, while the dominance index was significantly lower in MC than in YC and TO.

For the Margaleff index, no significant differences were found between $Y C$ and TO, both considering all beetle communities and the saproxylics only, probably due to the high abundance of some species ( $E$. fuscicollis, S. oblonga, A. fuscus), belonging to the Nitidulidae family.

\section{Survey of $\mathrm{MH}$ forms in the traditional fruit orchard}

A total of $495 \mathrm{MHs}$ was counted, with an

average of $41.2 \pm 6.4 \mathrm{ha}^{-1}$. In Fig. 4, the number of MHs per tree for each MHs form is reported.

Several MHs were absent (i.e., small, medium and large woodpecker breeding cavities, chimney trunk rot hole, woodpecker foraging excavation, fire scar, crack, bryophytes, foliose and fruticose lichens, ivy and lianas). Conversely, MHs occurring on stems and main branches (i.e., trunk base rot hole, trunk rot hole, semi-open trunk rot hole, dead branches) were the most abundant. Furthermore, MHs present at the trunk base (medium and large cavity) and on the main branches (insect galleries and boreholes, concavities) were quite frequent as well.

Those MHs appearing on cavities and tree injures were the most numerous ( 8 and 7 MHs per tree, respectively). The analysis of variance showed significant differences in the number of MHs per tree among the

Tab. 3 - Statistical parameters obtained from the PERMANOVA. The average values of the diversity indices are reported for young coppice (YC), mature coppice (MC) and the traditional fruit orchard (TO). Different letters indicate significant differences among the three agroforestry systems.

\begin{tabular}{llrrrrr}
\hline Group & Index & F-value & P-level & YC & MC & TO \\
\hline Saproxylics & Shannon & 154.48 & $<0.001$ & $1.912^{\mathrm{a}}$ & $2.450^{\mathrm{b}}$ & $1.138^{\mathrm{c}}$ \\
\cline { 2 - 7 } & Margaleff & 20.75 & 0.002 & $6.522^{\mathrm{a}}$ & $8.721^{\mathrm{b}}$ & $6.075^{\mathrm{a}}$ \\
\cline { 2 - 7 } & Equitability & 47.33 & $<0.001$ & $0.508^{\mathrm{a}}$ & $0.598^{\mathrm{a}}$ & $0.294^{\mathrm{b}}$ \\
\cline { 2 - 7 } & Dominance & 235.62 & -0.001 & $0.242^{\mathrm{a}}$ & $0.167^{\mathrm{b}}$ & $0.469^{\mathrm{c}}$ \\
\multirow{2}{*}{$\begin{array}{l}\text { Whole } \\
\text { community }\end{array}$} & Shannon & 82.31 & $<0.001$ & $3.063^{\mathrm{a}}$ & $3.285^{\mathrm{a}}$ & $2.182^{\mathrm{b}}$ \\
\cline { 2 - 7 } & Margaleff & 26.37 & 0.001 & $15.830^{\mathrm{a}}$ & $20.200^{\mathrm{b}}$ & $17.870^{\mathrm{a}}$ \\
& Equitability & 59.27 & $<0.001$ & $0.650^{\mathrm{a}}$ & $0.650^{\mathrm{a}}$ & $0.439^{\mathrm{b}}$ \\
& Dominance & 93.62 & $<0.001$ & $0.101^{\mathrm{a}}$ & $0.075^{\mathrm{a}}$ & $0.280^{\mathrm{b}}$ \\
\hline
\end{tabular}






Microhabitat forms

Fig. 4 - Number of MHs per tree for each $\mathrm{MH}$ form. The horizontal line indicates the median values; in the box, the lower limit corresponds to the value of the first quartile (Q1) of the distribution and the upper limit to the third quartile (Q3); the vertical lines (whiskers) delimit the intervals in which the lower values of Q1 (in the lower part) and the greater values of Q2 (in the upper part) are positioned. Outliers are reported as asterisks. Boxes with different letters indicate significant differences in the number of MHs between different $\mathrm{MH}$ forms $(\mathrm{p}<0.05)$.

different $\mathrm{MH}$ forms $\left(\mathrm{F}_{[6,133]}=52.47, \mathrm{p}<0.001\right)$. In particular, we observed three groups of MHs (group 1: Cavities, Tree injures; group 2: Crown deadwood, Epiphytic and Epixylic, Excrescens; group 3: Fresh exudates); no significant differences within groups were detected, while they occurred between the three groups. However, considering the second group, the number of "Excrescens" was not significantly different from that of "Fresh exudates". Fig. S1 in Supplementary material reports those pairs of $\mathrm{MH}$ forms significantly differing between each other after Tukey's test.

Fig. 5 shows the relationships (through Pearson's correlation coefficients) between the abundance of each family of saproxylics and the MH forms. The "Fruit- ing bodies of saproxylic fungi and slime moulds" was excluded since the associated MHs were absent.

Cleridae, Scraptiidae, Tenebrionidae and Throscidae were positively and significantly correlated with the "Cavities", representing $70 \%$ of the insect families. Only a few insect families (e.g., Elateride and Mordellidae) did not use cavities as MH. Furthermore, most of the families positively correlated with cavities were negatively correlated with the presence of "Tree injures and exposed wood", with the exception of the Tenebrionidae, which revealed high correlation with this MH form. The "Crown deadwood" significantly favored the abundance of many insect families.

About the $59 \%$ of the families (e.g., Cerambycidae, Curculionidae, Melyridae and Oedemeridae) were positively and significantly correlated with the "Excrescens" and "Epiphytes, epixylic and parasitic". The presence of these two MH forms, apparently, inhibited the occurrence of Elateride and Tenebrionidae. Only the Apionidae and Scarabaeidae were significantly and positively correlated with the "Fresh exudates", while no significant correlations were observed for all the other families.

The Anthicidae and Bruchidae were positively correlated with all $\mathrm{MH}$ forms, except for the "Excrescens", for which the correlations were negative. The Elateridae were negatively correlated with all $\mathrm{MH}$ forms, while the Oedemiridae were the only family positively correlated with all MH forms. Finally, several families revealed a random distribution (e.g., Nitidulidae, Cerambycidae, Curculionidae, Scarabaeidae, and Staphylinidae), since no correlations with the most abundand $\mathrm{MH}$ forms were observed.

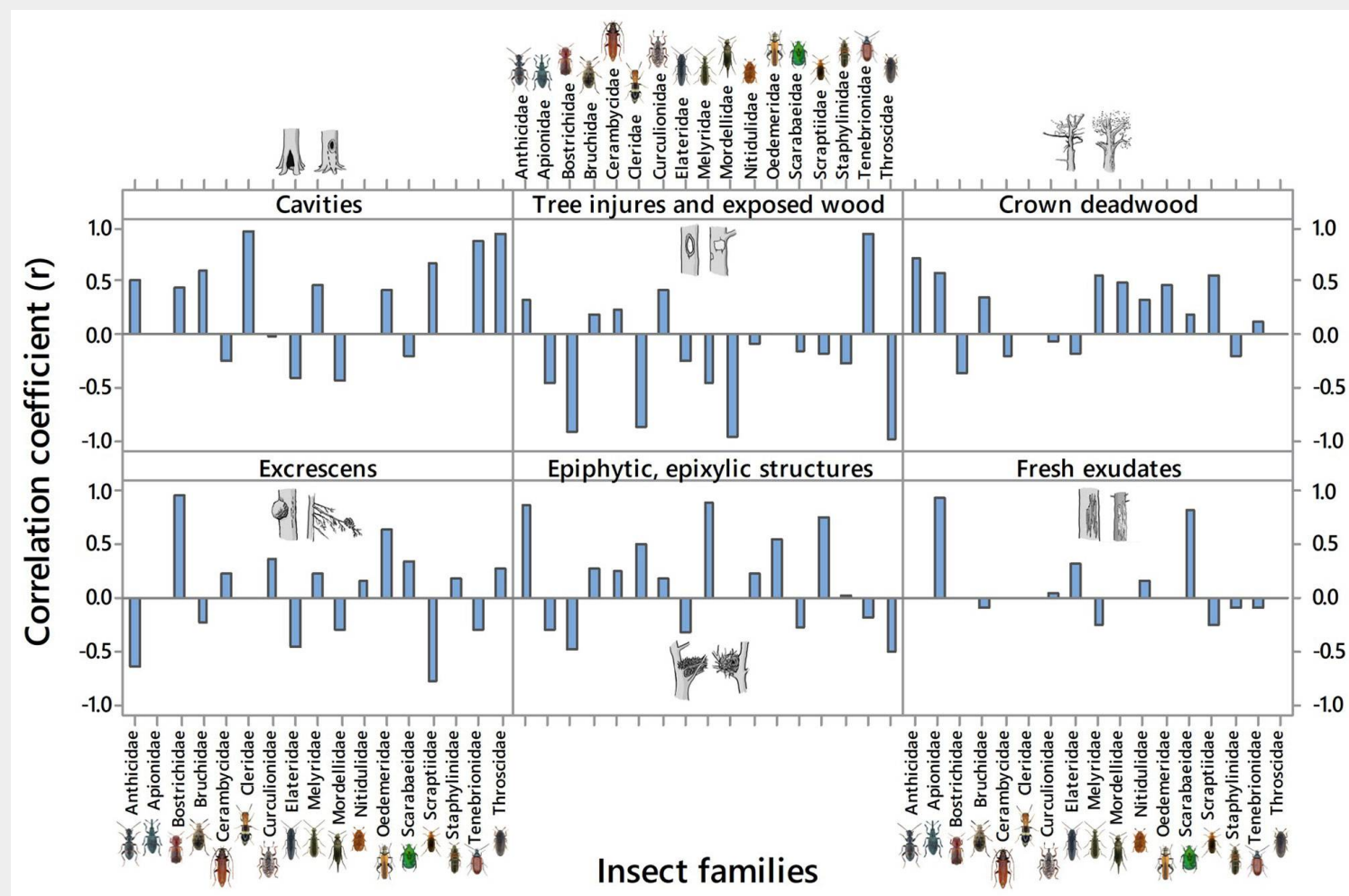

Fig. 5 - Correlation coefficients ( $r$ ) between the abundance of each family of saproxylic insects and the MHs forms. 


\section{Discussion}

Diversity and abundance of beetle communities in relationship with silvicultural treatments and $\mathrm{MH}$

\section{occurrence}

The $\alpha$-diversity of Coleoptera communities and saproxylic beetles was relatively high, in terms of species richness. The different management types had an impact on $\alpha$-diversity, confirming our first hypothesis. In fact, a lower number of species was found in MC (111 beetle species) than in YC and TO (164 and 145, respectively). Tree density in $M C$ was the highest among the tested management types, which, in combination with the associated structural traits (e.g., canopy cover, absence of deadwood) had a negative influence on $\alpha$-diversity of Coleoptera communities. The same trend occurred considering only the species included in the Red List (59 in YC, 43 and 47 species per MC and OT, respectively).

In MC all the trophic categories were uniformly present in terms of species and abundance (Fig. 2 - see also Tab S1 in Supplementary material). Whereas in TO saproxylic communities were characterized by xylophaguos and saproxylophauos species, which are involved in decomposition processes on branches and twigs, and useful for the development of larvae (Quinto et al. 2012). In YC, the xylophagous category prevailed, probably due to the presence of exposed stumps and twigs, inducing also a significant increase in the number of predators. These species enter the galleries made by xylophagus species or live in the small available spaces under the bark of recently dead trees (Siitonen 2012).

Among the various ecological parameters that influenced differences among sylvicultural systems (YC, MC, TO - 43 beetle species in total), in terms of diversity and abundance of species, available solar radiation represents a discrimination element between coppice stands and the fruit orchard (Salmon et al. 2008). The less dense canopy cover of TO probably promoted saproxylophagous and xylophagous species, though supporting only low abundances (Fahrig \& Merriam 1994). Moreover, in TO the canopy openness was a key element for saproxylic beetles, also in relationship with the resultant rich herbaceous layer. For example, Anthicidae and Bruchidae are closely linked to roots or seeds. In fact, their larvae develop in the soil, on leaf litter, and sometimes also under loose bark of trees, while adults are mostly saprophagous (Lawrence et al. 1995). Oedemeridae develop on fallen or standing tree trunks of large diameter, in tree hollows or in small, decaying branches. This taxon was positively related to all the surveyed $\mathrm{MHs}$. Their larvae live in rotting wood or in dead stems and roots (Sivilov et al. 2011).

Differences in solar radiation below the canopy occurred also between YC and MC, the latter being characterized by denser canopy cover, determining microclimatic conditions that allowed a more diversified beetle community. Horak (2014) argued that a high wealth of species is determined by a crown structure, recalling the conditions of solitary trees. In addition, Henneron et al. (2017) highlighted that a high canopy coverage reduces the diversity of predators. These patterns could be related to the effects of decreasing irradiance and temperature (Salmon et al. 2008).

In TO we found about $41 \mathrm{MHs}$ per ha, occurring on large trees. It is important to note that, although few $\mathrm{MH}$ forms were present in TO, they had a high frequency on each tree. The presence of large trees and the density of tree-related MHs significantly influenced the abundance of the different families of Coleoptera, suggesting a high variability between species that feed on deadwood or other substrates (Santopuoli et al. 2019). We also observed that TO was characterized by frequent and abundant sap beetles (Nitidulidae) and by rare predators and xylophagous that were, by contrast, more frequently found in $\mathrm{YC}$ and MC. Sap beetles were mostly saproxylophagous, linked to various decaying, fermenting or mouldy organic substrates, like oozing sap of wounded trees and other decaying organic substrates. We assume that the random distribution of saproxylophagous and others was influenced by the presence of organic compounds on the ground, mainly rotten fruits, which represents a source of food for many species of beetles (Nadeau et al. 2015). Trees in TO showed large stem diameters at breast height and were relatively old, which determined the open structure of their crowns, as such, suitable for species of beetles dependent on solitary and veteran trees (Ho- rak 2014). Overall, these observations confirm our second hypothesis. In detail, cavities had positive effects on Bostrichidae, Tenebrionidae and Throschidae, whose larvae feed under the bark, building galleries that accelerate the decomposition processes, improving the quality of available substrates for fungi and bacteria, and then the colonization by secondary saproxylic insects (Parisi et al. 2018), such as Cleridae and Melyridae (predators). Whereas, tree injuries and exposed wood were positively correlated with Cerambycidae, Curculionidae and Nitidulidae, probably in relationship with the absence of obstacles that facilitate spawning by adults of beetles (Quinto et al. 2015). The action of saproxylophagous and xylophagous beetle larvae expands cavities by feeding on wood and converting the wood into frass-borings and excrements that accumulate at the bottom of the cavity, together with the external inputs of leaves, twigs and seeds (Jönsson et al. 2004). Dermestidae and Staphylinidae showed positive correlation with epiphytes, epixylic and parasitic, adults carring out their biological cycle in the nests of birds or small mammals. Conversely, Mordellidae, Scraptiidae and Curculionidae were mainly linked to the root system of herbaceous plants and litter in TO. Cavities represent unique environments with a distinct community, also frequented by larvae of Elateridae. Their habits are not entirely clear, but many of the species caught were predators, probably opportunistic scavengers or saprophagous (Micó 2018).

Saproxylic beetles represented $34.3 \%$ of the whole beetle community and provided information on species diversity of the whole beetle community, confirming our third hypothesis. Among saproxylics, 22



Fig. 6 - A graphical representation of chestnut agroforestry systems and rural matrix considered fundamental for preserving saproxylic and non-saproxylic insects (drawings: G. Parisi; photo of Rutpela maculata: F. Parisi). 
out of 89 species are included in IUCN Red Lists (Tab. S1 in Supplementary material). In particular, for the vulnerable category, Xylopertha retusa (Bostrichidae) and Dromaeolus barnabita (Eucnemidae) develop in twig galleries, specifically in the sap wood; Ampedus sinuatus and Brachygonus megerlei (Elateridae) are predators of other saproxylic organisms. However, these species were sampled as single, or less than three, individuals. The rarity or highly localized presence could be explained by the low amount of deadwood, even of small size, and the associated absence of decomposition phases.

Implications for chestnut management Beetle community compositions differed among the three management methods, suggesting that a matrix of chestnut agroforestry systems should be used to improve conditions for biodiversity in this rural landscape (Fig. 6). Maintaining a patchy agroforestry landscape through the rotation of uses (Vacik et al. 2009) might help keep these beetle communities stable over time and space, ensuring their diversity and abundance, overall contributing to the conservation of biodiversity. Stand-specific management approach should be considered in relation to land-use planning and landscape design, as well as conservation needs and disturbance risks. Although coppice stands did not appear to be seriously endangered in terms of species richness (and the presence of endemic, rare and threatened species was a clear evidence of this), an excessive fragmentation of habitats in this vulnerable Mediterranean rural landscape, however, may reduce the connectivity between suitable areas and, thus, impeding saproxylics species with very limited dispersion capacity to recolonize those environments in which they extinguished or reach new habitats.

Landscapes with high density of veteran trees and high diversity of associated fauna should be preserved for conservation purposes (Siitonen \& Ranius 2015). General management rules can be envisaged to foster the biodiversity of saproxylic insects in these agroforestry systems (Parisi et al. 2018). Guidelines will be useful to implement habitat 9260 conservation measures at the national level: (a) maintain as many veteran trees as possible, also at the edge of coppice stands, allowing for natural aging of trees and favoring the formation of suckers, without a complete removal of dead branches simultaneously; (b) ensure the continuous supply of both young and mature trees. Continuity in the wood decay sequence is the most critical factor for the long-term persistence of highly specialized organisms; (c) avoid removing veteran trees rich in microhabitats useful for saproxylic fauna. Standing dead trees are valuable for saproxylic invertebrates, such as fallen ones; (d) make sure that deadwood can occur in moist and shaded areas, under partial shade or completely exposed to the sun. Furthermore, (e) avoid mowing between April and September; (f) use rotational management to generate a diversity of structures (Hjältén et al. 2017); (g) retain patches of woodland and scrub, especially where this provides blossom and additional deadwood; (h) plant small blocks of flowering trees on sites that lack spring nectar sources; (i) avoid any large-scale simultaneous woodland felling that suddenly exposes semi-shaded, veteran trees to full sunshine and wind; (I) manage hedges on a minimum three year rotation to create a range of species and structures across the landscape.

\section{Conclusions}

Beetle communities proved to be excellent bioindicators in chestnut agroforestry systems of the fragmented Mediterranean landscape in southern Italy. Forest management strategies should be oriented to diversify the territorial mosaic as much as possible, ensuring the presence of suitable habitats for keeping the populations of organisms in balance. The occurrence of $\mathrm{MHs}$ in managed chestnut agroforestry systems represents a valid ecological indicator for conservation purposes.

In this territorial matrix, mature orchards play a key role in the preservation of saproxylic and non-saproxylic beetle communities. Coppicing (YC, MC) and orchard management (TO) may add to natural disturbances, determining the rotation periods and creating landscape heterogeneity, thus influencing the biological cycle of beetle communities. In this sense, considering both spatial turnover and species richness of beetles allows a more comprehensive assessment of the processes contributing to species diversity than considering species richness only.

Our results highlighted that, in chestnut agroforestry systems, Coleoptera communities (particularly saproxylics) may help direct management practices aiming at biodiversity conservation. Restoring structural heterogeneity through flexible management strategies, considering the rural matrix, as well as structures and processes that would occur in the absence of human impact, may prevent excess loss of biodiversity in chestnut agroforestry systems. With this aim, further studies warrant to investigate chestnut coppices converted into high forests and abandoned coppices.

\section{Acknowledgments}

The authors thank the specialists of the various taxonomic groups: Paolo Audisio (Nitidulidae); Alessandro Bruno Biscaccianti (Alexiidae, Biphylidae, Cerylonidae, Dascillidae, Dermestidae, Erotylidae, Eucemidae, Laemophloeidae, Lathridiidae, Lucanidae, Mycetophagidae, Salpingidae, Scirtidae, Sphindidae, Tenebrionidae, Trogossitidae); Enzo Colonnelli (Anthribidae, Attelabidae, Brentidae, Curculionidae); Gianluca Magnani (Buprestidae); Massimo Faccoli (Curculionidae, Scolytinae); Fabrizio Fanti
(Cantharidae, Lampyridae); Emanuele Piattella (Scarabaeidae); Giuseppe Platia (Elateridae); Roberto Poggi (Staphylinidae Pselaphinae); Pierpaolo Rapuzzi (Cerambycidae, pars); Enrico Ruzzier (Mordellidae, Scraptiidae); Adriano Zanetti (Staphylinidae, pars). We are grateful to Bruno Lasserre (Università degli Studi del Molise, Italy) for technical support.

\section{References}

Angelini P, Casella L, Grignetti A, Genovesi P (2016). Manuali per il monitoraggio di specie e habitat di interesse comunitario (Direttiva 92/43/CEE) in Italia: habitat [Manuals for monitoring of species and habitat of community importance (Habitats Directive 92/43 /CEE) in Italy: habitat]. Serie Manuali e linee guida, ISPRA, Rome, Italy, pp. 142. [in Italian]

Audisio $\mathrm{P}$, Alonso-Zarazaga $M$, Slipinski A, Nilsson A, Jelínek J, Vigna Taglianti A, Turco F, Otero C, Canepari C, Kral D, Liberti G, Sama G, Nardi G, Löbl I, Horak J, Kolibac J, Háva J, Sapiejewski $M$, Jäch $M$, Bologna $M$, Biondi $M$, Nikitsky $N$, Mazzoldi $P$, Zahradnik $P$, Wegrzynowicz $P$, Constantin R, Gerstmeier R, Zhantiev R, Fattorini S, Tomaszewska W, Rücker W, Vazquez-Albalate X, Cassola F, Angelini F, Johnson C, Schawaller W, Regalin R, Baviera C, Rocchi S, Cianferoni F, Beenen R, Schmitt M, Sassi D, Kippenberg $H$, Zampetti M, Trizzino M, Chiari S, Carpaneto GM, Sabatelli S, De Jong Y (2015). Fauna Europaea: coleoptera 2 (excl. series Elateriformia, Scarabaeiformia, Staphyliniformia and superfamily Curculionoidea). Biodiversity Data Journal (3): e4750. - doi: 10.3897/BDJ.3.e4750

Bani A, Pioli S, Ventura M, Panzacchi P, Borruso L, Tognetti R, Tonon G, Brusetti L (2018). The role of microbial community in the decomposition of leaf litter and deadwood. Applied Soil Ecology 126: 75-84. - doi: 10.1016/j.apsoil.2018. 02.017

Bouchard P, Bousquet Y, Davies AE, Alonso-Zarazaga MA, Lawrence JF, Lyal CHC, Newton AF, Reid CAM, Schmitt M, Slipinski SA, Smith ABT (2011). Family-group names in Coleoptera (Insecta). ZooKeys 88: 1-972. - doi: 10.3897/zoo keys.88.807

Bouget C, Brustel H, Brin A, Noblecourt T (2008). Sampling saproxylic beetles with window flight traps: methodological insights. Revue d'Écologie 10: 21-32. [online] URL: http://documents. irevues.inist.fr/handle/2042/55807

Bouget C, Parmain G, Gilg O, Noblecourt T, Nusillard B, Paillet Y, Pernot C, Larrieu L, Gosselin F (2014). Does a set-aside conservation strategy help the restoration of old-growth forest attributes and recolonization by saproxylic beetles? Animal Conservation 17: 342-353. - doi: 10.1111/ acv.12101

Carpaneto GM, Baviera C, Biscaccianti AB, Brandmayr P, Mazzei A, Mason F, Battistoni A, Teofili C, Rondinini C, Fattorini S, Audisio P (2015). A red list of italian saproxylic beetles: taxonomic overview, ecological features and conservation issues (Coleoptera). Fragmenta Entomologica 47: 53-126. - doi: 10.4081/fe.2015.138

Conedera M, Manetti MC, Giudici F, Amorini E (2004). Distribution and economic potential of the Sweet chestnut (Castanea sativa Mill.) in Europe. Ecologia Mediterranea 30: 179-193. - doi: 
10.3406/ecmed.2004.1458

Dangles O, Jérôme C (2019). Ecosystem services provided by insects for achieving sustainable development goals. Ecosystem Services 35: 109-115. - doi: 10.1016/j.ecoser.2018.12.002

Dixon PM (1993). The bootstrap and the jackknife: describing the precision of ecological indices. In: "Design and analysis of ecological experiments" (Scheiner SM, Gurevitch J eds). Chapman and Hall, New York, USA, pp. 290-318. [online] URL: http://books.google.com/books? id $=$ pNpCoPe4mt4C

EC (2007). Interpretation manual of European habitats - EUR27. European Commission, DG Environment, Brussels, Belgium, pp. 142.

Fahrig L, Merriam G (1994). Conservation of fragmented populations. Conservation Biology 8: 50-59. - doi: 10.1046/j.1523-1739.1994.0801005 $0 . x$

Giannini R, Maltoni A, Mariotti B, Paffetti D, Tani A, Travaglini D (2014). Valorizzazione della produzione legnosa dei boschi di Castagno [Enhancement of the wood production from chestnut forests]. L'Italia Forestale e Montana 69: 307-317. [in Italian] - doi: 10.4129/ifm.2014.6. 01

Greco S, Infusino M, lenco A, Scalercio S (2018). How different management regimes of chestnut forests affect diversity and abundance of moth communities? Annals of Silvicultural Research 42: 59-67. - doi: 10.12899/asr-1503

Henneron L, Aubert M, Archaux F, Bureau F, Dumas $Y$, Ningre F, Richter $C$, Balandier $P$, Chauvat $M$ (2017). Forest plant community as a driver of soil biodiversity: experimental evidence from collembolan assemblages through large-scale and long-term removal of oak canopy trees Quercus petraea. Oikos 126: 420-434. - doi: 10.111 1/oik.03677

Hjältén J, Hägglund R, Löfroth T, Roberge JM, Dynesius M, Olsson J (2017). Forest restoration by burning and gap cutting of voluntary setasides yield distinct immediate effects on saproxylic beetles. Biodiversity and Conservation 26: 1623-1640. - doi: 10.1007/s10531-017-1321-0

Horak J (2014). Fragmented habitats of traditional fruit orchards are important for dead wood-dependent beetles associated with open canopy deciduous woodlands. Naturwissenschaften 101: 499-504. - doi: 10.1007/s00114-0141179-x

Infusino M, Greco S, Turco R, Bernardini V, Scalercio $S$ (2016). Managed mountain forests as diversity reservoirs in Mediterranean landscapes: new data on endemic species and faunistic novelties of moths. Bulletin of Insectology 69: 249-258. [online] URL: http://www. bulletinofinsectology.org/pdfarticles/vol69-201 6-249-258infusino.pdf

Joys AC, Fuller RJ, Dolman PM (2004). Influences of deer browsing, coppice history, and standard trees on the growth and development of vegetation structure in coppiced woods in lowland England. Forest Ecology and Management 202: 23-37. - doi: 10.1016/j.foreco.2004.06.035

Jönsson N, Méndez M, Ranius T (2004). Nutrient richness of wood mould in tree hollows with the scarabaeid beetle Osmoderma eremita. Animal Biodiversity and Conservation 27: 79-82. [online] URL: http://www.raco.cat/index.php/ $\mathrm{ABC} /$ article/view/56797
Larrieu L, Paillet $\mathrm{Y}$, Winter S, Bütler R, Kraus D, Krumm F, Lachat T, Michel AK, Regnery B, Vandekerkhove K (2018). Tree related microhabitats in temperate and Mediterranean European forests: a hierarchical typology for inventory standardization. Ecological Indicators 84: 194207. - doi: 10.1016/j.ecolind.2017.08.051

Lassauce A, Paillet Y, Jactel H, Bouget C (2011). Deadwood as a surrogate for forest biodiversity: meta-analysis of correlations between deadwood volume and species richness of saproxylic organisms. Ecological Indicators 11: 1027-1039. - doi: 10.1016/j.ecolind.2011.02.004 Lassauce A, Anselle P, Lieutier F, Bouget C (2012). Coppice-with-standards with an overmature coppice component enhance saproxylic beetle biodiversity: a case study in French deciduous forests. Forest Ecology and Management 266: 273-285. - doi: 10.1016/j.foreco.2011. 11.016

Lawrence JF, Newton AF, Pakaluk J, Slipinski SA (1995). Families and subfamilies of Coleoptera (with selected genera, notes, references and data on family-group named). Biology, Phylogeny, and Classification of Coleoptera 2: 7791006.

Lindenmayer DB, Margules CR, Botkin DB (2000). Indicators of biodiversity for ecologically sustainable forest management. Conservation Biology 14: 941-950. - doi: 10.1046/j.15231739.2000.98533.x

Manning P, Slade EM, Beynon SA, Lewis OT (2016). Functionally rich dung beetle assemblages are required to provide multiple ecosystem services. Agriculture, Ecosystems and Environment 218: 87-94. - doi: 10.1016/j.agee.2015. 11.007

Marti JA (2001). A new method for non-parametric multivariate analysis of variance. Austral Ecology 26: 32-46. - doi: 10.1111/j.1442-9993.2001. 01070.pp.x

Mattioli W, Mancini LD, Portoghesi L, Corona P (2016). Biodiversity conservation and forest management: the case of the sweet chestnut coppice stands in Central Italy. Plant Biosystems 150: 592-600. - doi: 10.1080/11263504.2015. 1054448

McArdle BH, Anderson MJ (2001). Fitting multivariate model to semi-metric distances: a comment on distance-based redundancy analysis. Ecology 82: 290-297. - doi: 10.1890/0012-9658 (2001)082[0290:FMMTCD]2.0.CO;2

Micó E (2018). Saproxylic insects in tree hollows. In: "Saproxylic Insects: Diversity, Ecology and Conservation" (Ulyshen MD ed). Springer, Cham, Heidelberg, pp. 693-727. - doi: 10.1007/ 978-3-319-75937-1_21

Moning C, Müller J (2009). Critical forest age thresholds for the diversity of lichens, mollusks and birds in beech (Fagus sylvatica L.) dominated forests. Ecological Indicators 9: 922-932. doi: 10.1016/j.ecolind.2008.11.002

Mosconi F, Campanaro A, Carpaneto GM, Chiari S, Hardersen S, Mancini E, Maurizi E, Sabatelli S, Zauli A, Mason F, Audisio P (2017). Guidelines for the monitoring of the saproxylic beetles protected in Europe. Nature Conservation 20: 23-264. - doi: 10.3897/natureconservation.20.12 688

Nadeau P, Thibault M, Horgan FG, Michaud JP, Gandiaga F, Comeau C, Moreau G (2015). Decay- ing matters: Coleoptera involved in heterotrophic systems. In: “Beetles: Biodiversity, Ecology and Role in the Environment" (Stack C ed). Nova Science Publishers Inc., Hauppauge, New York, USA, pp. 123-174. [online] URL: http:// www.researchgate.net/publication/272747071

Paillet $\mathrm{Y}$, Archaux F, Boulanger V, Debaive N, Fuhr M, Gilg O, Grosselin F, Guilbert E (2017). Snags and large trees drive higher tree microhabitat densities in strict forest reserves. Forest Ecology and Management 389: 176-186. doi: 10.1016/j.foreco.2016.12.014

Paillet Y, Debaive N, Archaux F, Cateau E, Gilg O, Guilbert E (2019). Nothing else matters? Tree diameter and living status have more effects than biogeoclimatic context on microhabitat number and occurrence: an analysis in French forest reserves. PLoS One 14 (5): e021650o. doi: 10.1371/journal.pone.0216500

Parisi F, Lombardi F, Sciarretta A, Tognetti R, Campanaro A, Marchetti M, Trematerra $P$ (2016). Spatial patterns of saproxylic beetles in a relic silver fir forest (Central Italy), relationships with forest structure and biodiversity indicators. Forest Ecology and Management 381: 217-234. - doi: 10.1016/j.foreco.2016.09.041

Parisi F, Pioli S, Lombardi F, Fravolini G, Marchetti M, Tognetti R (2018). Linking deadwood traits with saproxylic invertebrates and fungi in European forests - a review. iForest 11: 423-436. doi: 10.3832/ifor2670-011

Parisi F, Di Febbraro M, Lombardi F, Biscaccianti $A B$, Campanaro A, Tognetti R, Marchetti $M$ (2019). Relationships between stand structural attributes and saproxylic beetle abundance in a Mediterranean broadleaved mixed forest. Forest Ecology and Management 432: 957-966. doi: 10.1016/j.foreco.2018.10.040

Parisi F, Frate L, Lombardi F, Tognetti R, Campanaro A, Biscaccianti AB, Marchetti M (2020). Patterns of saproxylic species richness and diversity of Coleoptera communities in unmanaged forests of Mediterranean mountains. Ecological Indicators 110: 105873. - doi: 10.1016/j.eco lind.2019.105873

Persiani AM, Lombardi F, Lunghini D, Granito VM, Tognetti R, Maggi O, Pioli S, Marchetti M (2015). Stand structure and deadwood amount influences saproxylic fungal biodiversity in Mediterranean mountain unmanaged forests. iForest 9: 115-124. - doi: 10.3832/ifor1304-008

Quinto J, Marcos-García MA, Díaz-Castelazo C, Rico-Gray V, Brustel H, Galante E, Micó E (2012). Breaking down complex saproxylic communities: understanding subnetworks structure and implications to network robustness. PLoS One 7 (9): e45062. - doi: 10.1371/journal.pone.0045 062

Quinto J, De Los Angeles Marcos-García M, DíazCastelazo C, Rico-Gray V, Galante E, Micó E (2015). Association patterns in saproxylic insect networks in three Iberian Mediterranean woodlands and their resistance to microhabitat loss. PLoS One 10 (3): e0122141. - doi: 10.1371/ journal.pone.0122141

Redolfi De Zan L, Bellotti F, D’Amato D, Carpaneto GM (2014). Saproxylic beetles in three relict beech forests of central Italy: analysis of environmental parameters and implications for forest management. Forest Ecology and Management 328: 229-244. - doi: 10.1016/j.foreco. 
2014.05.040

Sabatini FM, Burrascano S, Azzella MM, Barbati A, De Paulis S, Di Santo D, Facioni L, Giuliarelli D, Lombardi F, Maggi O, Mattioli W, Parisi F, Persiani A, Ravera S, Blasi C (2016). One taxon does not fit all: herb-layer diversity and stand structural complexity are weak predictors of biodiversity in Fagus sylvatica forests. Ecological Indicators 69: 126-137. - doi: 10.1016/j.ecol ind.2016.04.012

Salmon S, Artuso N, Frizzera L, Zampedri R (2008). Relationships between soil fauna communities and humus forms: response to forest dynamics and solar radiation. Soil Biology and Biochemistry 40: 1707-1715. - doi: 10.1016/j.soil bio.2008.02.007

Santopuoli G, Di Cristofaro M, Kraus D, Schuck A, Lasserre B, Marchetti M (2019). Biodiversity conservation and wood production in a Natura 2000 Mediterranean forest. A trade-off evaluation focused on the occurrence of microhabitats. iForest 12: 76-84. - doi: 10.3832/ifor2617-011 Siitonen J (2012). Threatened saproxylic species. In: "Biodiversity in Dead Wood" (Stokland JN,
Siitonen J, Jonsson BG eds). Cambridge University Press, New York, USA, pp. 356-379.

Siitonen J, Ranius T (2015). The importance of veteran trees for saproxylic insects. In: "Europe's Changing Woods and Forests: From Wildwood to Managed Landscapes" (Kirby K, Watkins C eds). CABI, Wallingford, UK, pp. 140153. - doi: 10.1079/9781780643373.0140

Sivilov O, Atanassova J, Zlatkov B (2011). Food plant spectrum of Oedemeridae species (Insecta, Coleoptera) based on pollen analysis (a preliminary study). Comptes Rendus de l'Académie Bulgare des Sciences 64 (2): 225-230.

Stokland JN, Siitonen J, Jonsson BG (2012). Biodiversity in dead wood. Cambridge University Press, Cambridge, UK, pp. 524. - doi: 10.1017/CB O9781139025843

Tabacchi G, Di Cosmo L, Gasparini P (2011). Aboveground tree volume and phytomass prediction equations for forest species in Italy. European Journal of Forest Research 130: 911-934. - doi: 10.1007/s10342-011-0481-9

Vacik H, Zlatanov T, Trajkov P, Dekanic S, Lexer MJ (2009). Role of coppice forests in maintain- ing forest biodiversity. Silva Balcanica 10: 35-45. [online] URL: http://www.researchgate.net/pu blication/285667129

Zlatanov T, Schleppi P, Velichkov I, Hinkov G, Georgieva M, Eggertsson O, Zlatanova M, Harald $V$ (2013). Structural diversity of abandoned chestnut (Castanea sativa Mill.) dominated forests: implications for forest management. Forest Ecology and Management 291: 326-335. doi: 10.1016/j.foreco.2012.11.015

\section{Supplementary Material}

Fig. S1 - Differences of means for the occurring forms of MHs after Tukey test.

Tab. S1 - List of species of Coleoptera and number of specimens collected from young coppice (YC), mature coppice (MC) and traditional fruit orchard (TO).

Link: Parisi_3478@supploo1.pdf 